\title{
A autonomia e a instrumentalidade do Direito numa perspectiva superestrutural'
}

\author{
Autonomy and Instrumentality of Law in a superestructural perspective
}

Csaba Varga ${ }^{2}$

1 Este artigo é uma homenagem ao professor Zoltan Peteri, um dos mais influentes organizadores, acadêmicos e professores que tiveram um papel pioneiro na revitalização do espírito do Direito Comparado como uma opção metodológica para a pesquisa jurídica na Hungria - uma grande realização especialmente para aqueles longos períodos de socialismo de inspiração moscovita, que governou "acima de qualquer suspeita ou oposição", e que direcionava idéias e metodologias não genuinamente inerentes ao Marxismo. O professor Peteri abordou questões jurídicas basilares - ou, propriamente, eternas - quais sejam: questões de tradição jurídica local, Direito e valores, princípios gerais do Direito, Direito natural e direitos fundamentais. A forma pela qual o professor Peteri abordou tais questões manteve um padrão disciplinar de reação intelectual avesso às normas estabelecidas - num período em que a opressão permeou a vida quotidiana, em resposta à Revolta de 1956 na Hungria. $\mathrm{O}$ autor deste artigo trabalha com Peteri em estreita relação já há mais de trinta e cinco anos nas Seções de Direito Comparado e Filosofia do Direito do Instituto de Estudos Jurídicos da Academia Húngara de Ciências e tem construído, nos últimos anos, em cooperação ativa com ele, um novo regime de educação jurídica em disciplinas do Direito desde a fundação do Instituto de Filosofia do Direito da Universidade Católica Pázmány Péter da Hungria, sob as condições "pós-comunistas". Traduzido de Autonomy and Instrumentality of Law. Artigo publicado na revista Acta Juridica Hungarica, vol. 40, p. 213-235, Budapeste, 2000. Tradução de Thiago Arcanjo Calheiros de Melo. Contato: thiagoacmelo@gmail.com.

2 Pesquisador do Instituto de Ciências Jurídicas e Administrativas da Academia Húngara de Ciências, em Budapeste; um dos refundadores da Universidade Católica da Hungria, na qual é professor de Filosofia do Direito; é autor de diversos livros de Filosofia do Direito e Teoria Geral do Direito; também tem experiência na área de Educação, atuando na coordenação de projetos da União Européia; é fundador de diversas revistas (inclusive Current Legal Theory, Ratio Juris, bem como Legal Theory); professor visitante das faculdades de Lund, Camberra, Waseda / Tóquio, Yale / New Haven, Edimburgo, Münster e Estocolmo. Mais informações nos sítios: <http://www.jak.ppke.hu e http://www.thomasinternational.org> . 
Resumo: Este artigo tem por objetivo discutir aspectos fundamentais da relação entre base e superestrutura. Centrando-se principalmente na relação entre economia e sociabilidade, expõe, criticamente, como o tema foi tratado pelos "marxismos". Discutindo estas questões, expõem-se as respectivas conseqüências para a compreensão do Direito, delineando-se, sob uma nova perspectiva, alguns potenciais proveitos para sua teorização.

Palavras-chave: Base e superestrutura; Marxismo; Economia; Direito Abstract: This paper aims to discuss fundamental aspects of relation between basis and superstructure. Focusing mainly on relation between economy and sociability, it explains, critically, the treatment of subject by "marxisms". Discussing these issues, it explains respective consequences to understanding of law, outlining, in a new approach, some potential advantages to legal theorizing.

Keywords: Basis and superstructure; Marxism; Economy; Law

\section{INTRODUÇÃO}

Os conceitos também podem ter um estranho destino. Isto é ainda mais verdadeiro se forem empregados em funções diferentes da original enquanto mantêm a aparência de identidade conceitual. Desse modo, ao retirar os conceitos das funções as quais foram inicialmente destinados a cumprir e ao empregá-los em um ambiente estranho à sua natureza, suas reais determinações não mais podem predominar - se é que tal utilização não os coloca de cabeça para baixo. Se alguns conceitos têm de enfrentar uma tal sorte, eles, no meio em que foram empregados, conseguem causar seguramente mais polêmica que ajudar ao esclarecimento. Antes de tudo, se desejamos vencer disfunções latentes, temos de torná-las manifestas. De forma semelhante, poderemos esclarecer as relações conceituais somente quando seus significados e funções originais forem revelados em seus contextos originais. 
Se examinássemos os ensinamentos do Marxismo - circunscrevendo-o ao que Engels chamou de a concepção materialista da história ${ }^{3}$ - a resposta certamente incluiria as categorias de base e superestrutura e expressaria as conclusões a que Karl Marx chegou após décadas de pesquisa. Essas duas categorias, entretanto, sendo uma formulação concisa e metafórica de uma pressuposição acadêmica, iniciaram um caminho independente já na época de Marx. Este pressuposto, ao coordenar uma investigação científica, isto é, uma hipótese de trabalho, primeiramente avançou como uma proposição acadêmica tomada como suficiente em si e de si mesma, e, por isso, tornada doutrina: o sistema de certas proposições fundamentais. Isto implica uma completa alteração de funções. Desde então, tudo aquilo que fora o ponto de partida tornou-se a conclusão final. Em conseqüência, suas deduções aparentemente concretas já não podem ser chamadas mais de provas, uma vez que têm como única possibilidade a ilustração de uma verdade. Esse tipo de tratamento dos conceitos impulsionou um enrijecimento teórico, direcionando, portanto, outros conceitos para caminhos forçados. Quando uma teoria permeada por tais conceitos pretende restar consistente consigo mesma, estes caminhos forçados irradiam-se em uma espécie de reação em cadeia, impregnando a teoria completamente; em última análise, lideram a deformação da totalidade da teoria. Isto implica uma completa e inevitável incerteza conceitual.

Considerando que o Direito é primordialmente, para a tradição da teoria marxista, um fenômeno superestrutural, a avaliação filosófica das categorias da base e superestrutura pode, durante longos períodos, influenciar diretamente a explanação filosófica do Direito na órbita do Marxismo. Todavia, por mais que o fundamento da concepção do Direito como um componente superestrutural da teoria jurídica marxista possa parecer um princípio, a incerteza inerente a seu conteúdo só cresce e faz com que o silêncio da crítica esteja à beira de se transformar em crítica do silêncio.

3 "Materialistiche Auffassung der Geschichte" (MARX; ENGELS, 1951, p. 343); ou "Wir kennen nur eine cinzige Wissensehaft, die Wissenschaft der Geschichte." (MARX; ENGELS, 1951, p. 343). 
Um razoável esclarecimento suporia retrabalhar a filosofia marxista nos níveis dos modernos ${ }^{4}$ e pós-modernos ${ }^{5}$ e novas análises em todos os campos, com vistas a retornar às origens do pensamento metodológico de Marx - em suma, isto suporia aquilo que G. Lukács chamou de renascimento do Marxismo. Na ausência disto, a teoria jurídica deve, no mínimo, esclarecer quais os pressupostos metodológicos e resultados teóricos a exposição do pensamento jurídico apresenta com a utilização das categorias "base e superestrutura". Além disso, a mesma teoria deve deixar claro por que razões e de que forma construiu o conceito representante de sua própria mudança.

No que se segue, em um primeiro tratamento, o significado original do tema e das funções das categorias "base e superestrutura" foram reconstruídos. Após, foram delineados em seus fundamentos (seus princípios e origem) as deformações do entendimento teórico do Direito, bem como seu enrijecimento em um completo doutrinarismo (cf. VARGA, 1986, pp. 1-2 e 35 e ss.). Em seguida, tentei levantar algumas questões atuais da interpretação filosófica relacionadas a essas categorias, delineando alguns proveitos potenciais e conteúdos teóricos decorrentes da utilização das mesmas na teorização jurídica.

\section{UMA CATEGORIA RELACIONAL}

Como é usual com esta específica tradição do pensamento, as categorias base e superestrutura têm desempenhado, neste último século e meio de desenvolvimento, uma função ideológica conforme as mais

4 Para um estudo abrangente acompanhado pela avaliação global da contribuição teórica do Marxismo para os estudos jurídicos, cf. Marxian Legal Theory, com organização e introdução de Csaba Varga (1993) xxvii + 530 [The International Library of Essays in Law \& Legal Theory, Schools 9]. Para um panorama sobre o estado atual da teoria jurídica, cf. Csaba Varga: "Jogtudományunk az ezredvégen" [com o resumo "Legal Scholarship at Threshold of a New Millenium" (pp. 347-349)], em Iustum, aequum, salutare Emlekkönyv Zlinszky János tiszteletére (BANREVY, JOBBAGYI, VARGA, 1889, p. 298-314), organizado por Gábor Banrevy, Gábor Jobbágyi, Csaba Varga (Budapeste [Osiris] 1998), 298-314 [A Pazmany Peter Katolikus Egyetem Jog - és Államtudományi Karának könyvei 1], em breve em inglês in Rechtstheorie Beiheft, (KRAWIET, VARGA, 2000).

5 Sobre as possibilidades do Marxismo em relação às teorias pós-modernas, cf., e.g., Transition to Rule of Law On the Democratic transformation in Hungary, particularmente os capítulos "No-law" e "Rule of Law" (VARGA, 1995, p. 19 e ss. e p. 156 e ss) [Philosophiae luris]. 
variadas práticas políticas. Isto explica por que as categorias base e superestrutura - as quais, em caso de classificações e rotulações, implicam conseqüências que não exigem novas perguntas - têm se tornado questões fundamentais para o materialismo histórico - entendido como uma prática política propriamente dita.

A reconstrução de seu genuíno significado, colocando as categorias em seu devido lugar para que se possa ao mesmo tempo apresentar o melhor de sua comunicabilidade e de sua fundamentação na teoria, é uma questão ainda a ser cumprida (se é que isso ocorrerá), em todos os seus aspectos, e carrega consigo uma dupla tarefa - os resultados finais até agora obtidos têm avançado como sugestões sob influência do renascimento do Marxismo conforme indicado pela póstuma Ontologia do Ser Social de G. Lukács. Ela implica, primeiramente, a reconstrução do sistema de idéias de Marx mediante um retorno à identificação das perspectivas metodológicas formuladas em sua obra. Em segundo lugar, ela exige a análise dos períodos passados com seus preconceitos, pressupostos bem como toda a mentalidade característica de Marx, o que obviamente resultará em novas análises e avaliações conforme as necessidades do presente - se bem que respondendo a antigos questionamentos.

A literatura filosófica, sob o controle do "socialismo realmente existente" das últimas décadas, na Hungria, para retornar às considerações metodológicas do próprio Marx, destacou, acima de tudo, as características relativas às categorias base e superestrutura. Assim, base e superestrutura não são categorias inteligíveis em si mesmas, mas, somente "como categorias correlacionadas, elas dão expressão a uma natureza una, objetiva na realidade, da relação entre dois lados" (RÓNAI, 1973, p. 23). Elas não servem à "invenção" da realidade social, uma vez que elas meramente servem para caracterizar fenômenos já descritos por outras categorias. Sua serventia, a partir de uma dada perspectiva, é: expressar a "reciprocidade e conexão" de totalidades heterogêneas umas em relação às outras (KALLÓS, ROTH, 1978, p. 156). Por esta razão, elas não têm "autonomia e significação independentes"; logo, devemos ressaltar a categoria da "relação entre base e superestrutura" em vez de "base e superestrutura" (BAUMAN, 1967, 
p. 117). Por outro lado, isto não necessariamente descarta aquelas expressões metafóricas e ilustrativas (Idem) que foram emprestadas da arquitetura (KALLÓS, ROTH, 1978, p. 156). Reconhecer a origem metafórica, entretanto, não é decisivo por si só. Pode apenas se tornar decisivo na medida em que colocamos a expressão em seu ambiente contextual de origem. Neste caso, torna-se notório que Marx verdadeiramente não exclui a autonomia relativa da superestrutura (nem verdadeiramente ele a confirma) (MAKEPEACE, 1980, p. 20); isto é, existe uma diferença entre as investigações concretas de Marx e as generalizações relativas à questão de as influências entre base e superestrutura serem bilaterais ou recíprocas (PHILLIPS, 1980, p. 201).

O último período histórico, em termos de filosofia do Marxismo na Hungria antes da queda do regime comunista imposto - em oposição aos primeiros períodos, isto é, aqueles de simplificação stalinista, que aceitavam a superestrutura somente como a formação homogênea de classe decorrente de uma base que carregava em si conteúdos classistas - afirmou inequivocamente, também de uma perspectiva classista, que a superestrutura é multi-facetada (KARPÁTI, 1982, pp. 8-10; RÓNAI, Op. Cit., p. 21). Contudo, por mais estranho que possa parecer, isto não significa mais do que aquilo que Antônio Gramsci formulou há meio século: "a base e a superestrutura formam um bloco histórico, o complexo, uma totalidade contraditória e heterogênea de uma superestrutura que é o reflexo de uma totalidade de relações sociais de produção" (GRAMSCI, 1970, p. 94). A circunstância em que Gramsci fala de superestruturas no plural em relação à dada base é auto-evidente, uma vez que nós empregamos o conceito de superestrutura como um termo genérico desde o início. Depreende-se também dessa colocação que a superestrutura pode apenas existir em oposição à base. Isto é, a superestrutura concilia estes fenômenos heterogêneos que representam um tipo de generalidade somente em um aspecto: como totalidades, as superestruturas têm relações específicas em relação ao grupo de fenômenos sociais indicados como sua base.

Ressalto que tal caracterização da superestrutura exclui desde o início qualquer outra perspectiva em relação ao papel a ser desempe- 
nhado por ela na qualificação de um fenômeno como superestrutura. O mínimo conceitual aceitável é tal qual aquele desenvolvido pela Ontologia de Lukács, ou seja, é como uma exigência para todos os componentes da existência social; é como um requisito para fazer com que estes componentes apareçam em uma forma capaz de exercer influência social (qualquer que seja ela). Portanto, neste contexto, mesmo que a verdadeira influência própria da superestrutura não seja muito determinante para outras superestruturas; ainda que tal influência não esteja a se fazer sentir intensa e extensamente; e ainda que as bases da superestrutura possam ser consideradas típicas de outros casos, a verdadeira influência da superestrutura dificilmente configurará sua natureza. Conseqüentemente, isto pode ser ou uma grande retórica ou apenas uma feliz terminologia, visto que isto não tem qualquer conteúdo e que agora a superestrutura foi degradada a uma "subestrutura" - se julgarmos que ela assim conceituada apresenta uma influência menor do que inicialmente esperávamos (HERMANN, 1980).

Conceber base e superestrutura como categorias relacionais explica porque um mínimo de influência já é o suficiente; quer dizer, a relação deve ser traçada sempre em concreto, historicamente e em grau definido. Sendo assim, a natureza e a característica desse mínimo evidenciariam a relação entre base e superestrutura, tendo em vista que o desenho desse mínimo conceitual visa fronteiras externas, e, por isso, ele não faz muito mais do que dizer que o único conteúdo dessas categorias relacionais é a conexão das diversas áreas; um fato que é precisa e exclusivamente manifesto na sua recíproca influência.

Se dissermos, utilizando a linguagem da Ontologia de Lukács, que a existência social é um processo de avanço irreversível no qual tem lugar a recíproca influência das respectivas complexidades, então, torna-se evidente que base e superestrutura são apenas o âmbito no qual esta recíproca influência se manifesta (o equivalente à existência social na perspectiva da Ontologia de Lukács). Considerando que a categoria é relativa; que recebe ela mesma tal significação da recíproca influência e do movimento incessante expresso no seu dinamismo, a própria categoria será motivo de desentendimento; mais que isso, será claramente enganosa, se, em vez de uma dinâmica de funciona- 
mento- ao descrevermos a superestrutura-, indicarmos um estaticismo ou uma objetividade imóvel, expressa num estado de repouso. Isto é típico de definições exemplificativas (ERDÉLYI, 1980, p. 95), que apresentam a superestrutura mais como um corte transversal e anatômico do que um organismo vivo que "realmente" exerce influência (o que nos faz lembrar da caracterização lukacsiana do materialismo mecânico, segundo o qual, no fundo, o materialismo vulgar utiliza padrões a partir de um ponto-de-vista (visão de mundo) quase-religioso, na forma de metáforas de alguns "criadores" ativos e de umas passivas "criaturas" (LUKÁCS, 1976, pp. 350 e ss).

Independentemente de quais os critérios que estabelecemos para tais fenômenos, a sua presença real e importância só são percebidos no movimento e dinamismo dos fenômenos em questão. Isto é claramente demonstrado por Lukács na análise da posição de classe e da ideologia. Por não haver limites previamente traçados, os seres humanos tomam parte nas lutas sociais com todo o seu intelecto, e, por isso mesmo, qualquer afirmação ou negação de uma declaração é definida a partir da perspectiva de classe. Portanto, a fronteira onde uma ideologia termina e outra começa não pode ser traçada sem se considerar o contexto total em que estão imersas, uma vez que o caráter de tal distinção "não é inerente à declaração abstrata em si mesma" (LUKÁCS apud HOLZ, KOFLER, ABENDROTH, 1974, pp. 43-44). As respostas a essas perguntas podem ser sempre reveladas a partir do próprio movimento do fenômeno e dos processos históricos concretos, no curso de como ele vai ser finalmente definido. Evidentemente, isto não significa reconhecer que temos um romance a percorrer, mas a mera aplicação das idéias metodológicas de Marx. É também um princípio fundamental da Ontologia de Lukács, segundo a qual a existência social, semelhantemente a outros tipos de existência, é um processo de avanço irreversível.

Salientar a natureza dinâmica da superestrutura exclui a possibilidade de concebê-la como um meio passivo com relação à base; exclui a natureza de que "essa define aquela de forma absoluta pela força das leis da natureza" (LUKÁCS, 1976, p. 520). Base e superestrutura não são meios oponíveis um ao outro em razão de algum tipo de repulsão; 
seus tratamentos como categorias relativas podem apenas ser cotejados a partir de sua inseparabilidade, aceita previamente. "Base e superestrutura como categorias correlatas expressam a relação entre dois lados objetivamente inseparáveis na realidade" (RONAI, op. cit., p. 23). Isto abarca os limites da metáfora "base" e "superestrutura" e deixa claro que seu significado emprestado de arquitetura não pode ser transferido indistintamente para todas as áreas (KALLÓS-ROTH, op. cit., p. 160).

Na sua utilização arquitetônica, a base não tem uma função independente. Sua função é meramente instrumental, subordinada e desenvolvida estaticamente. Ela é concebida para apoiar a superestrutura e facilitar a sua auto-realização. No que diz respeito à relação entre a economia e outras esferas, o que é precisamente importante é a função instrumental daquela esfera. A economia assume funções e valores relativamente independentes, mas estes foram transformados em absolutos pela concepção stalinista ao imputar ao processo da história uma teleologia emprestada de uma visão de mundo quase-religiosa. Ao mesmo tempo, na arquitetura, a criação da base e da superestrutura é uma seqüência de um rigoroso processo de sucessão que, mesmo sendo irreversível, pode arruinar-se a qualquer momento. Caso isso ocorra, a construção não será concluída, mas ainda assim ela poderá ser considerada completa na proporção do nível e da medida de seu acabamento num dado momento. Foi essa noção de sucessão e de fundação prévia que levou o pensamento filosófico a um beco sem saída, quando, em vez de partir da inseparável inter-relação, supôs que uma base pode ter sido criada por si só, que ela por si criaria uma superestrutura adequada a ela mesma.

Quando se fala da relação entre base e superestrutura, nós já estabelecemos que só podem ser levantados questionamentos acerca destes problemas se levarmos em consideração o número total de inter-relações entre as totalidades e somente se considerarmos a relação como a de dois lados inseparáveis. Saber como esta questão é apreendida dentro da filosofia marxista é de fundamental importância, embora não tenha sido adequadamente formulada até hoje. No esforço para desvelar as múltiplas inter-relações, poderemos ver como 
eram sutis as conclusões formuladas por Marx a respeito da análise sócio-econômica, em suas primeiras tentativas; como e por que estas formulações a respeito do sistema de relações sociais mais tarde se tornaram um sistema de "frente e verso" nas generalizações dos clássicos do Marxismo; como, por sua vez, um maior uso e simplificação, ao acarretar distorções teóricas, convenceram Engels a reconstruir o sistema de relações, em seus últimos escritos, também no plano da generalização teórica, em sua verdadeira complexidade; e, finalmente, como tudo isto quase se transformou num determinismo mecânico na teorização stalinista (cf. VARGA, 1986) - acima de tudo, para justificar a prática política voluntarista, atraindo o par base/superestrutura para a névoa de uma profecia quase auto-realizável.

$\mathrm{Na}$ Hungria, no início dos anos 80 (e quase desaparecendo no início dos anos 90), após esses antecedentes, a filosofia do Marxismo, no intuito de reconstruir o sistema metodológico de Marx, procurou pontos de apoio para corrigir as distorções da era anterior. Na verdade, as tentativas foram muitas. No presente artigo, com vistas a embasar uma reflexão filosófica atual e a partir de uma dada perspectiva metodológica, posso apenas apresentar um conjunto de exemplos representativos dessas tentativas.

Uma das abordagens buscou a moderna formulação do papel determinante (em última instância) da economia, comparando e reformulando as relevantes posições assumidas pelos clássicos do Marxismo neste particular. "O que nós não reconhecemos é que as idéias e opiniões podem ter um desenvolvimento independente das condições econômicas. Idéias sempre se originam sobre o solo de certas condições econômicas - isto é, a base econômica -, mas, depois de nascerem, reagem sobre esta base, influenciam seu desenvolvimento e desempenham papel social ativo" (KÁRPÁTI: op. cit., p. 16). Esta abordagem demonstra claramente os esforços na eliminação dos resquícios da abordagem mecânico-determinista e apresenta as inter-relações manifestas na existência social, em sua interação dialética. Graças à sua perspicácia, esta formulação é dificilmente refutável, mas é questionável quanto a ser uma resposta completa, uma vez que sugere que um sistema de condições econômicas (uma espécie de base) poderia 
aparentemente ser criado sozinho, sem qualquer interação com algum tipo de superestrutura, como se algo pudesse existir antes e depois no curso do desenvolvimento da base e da superestrutura.

Outra abordagem procurou dar respostas através da teoria leninista do reflexo. Segundo tal teoria, o ponto de referência é o estabelecimento de que a "superestrutura reflete a base econômica". O verdadeiro significado logo veio à tona após a noção-chave ter sido interpretada: "Nós chamamos de fenômeno da reflexão os processos dentro de um dado sistema que têm um impacto sobre outro sistema." (KALLÓS-ROTH, op. cit., p. 162) O conceito de reflexo, assim definido, não é nem de longe algo livre de problemas. Isto auxilia a sobrevivência da tendência teórica que, durante o desenvolvimento do Marxismo no século XX, empregou uma abordagem epistemológica progressiva, exclusiva e distorcidamente à revelia de uma perspectiva ontológica - e que exerceu uma forte influência negativa sobre Lukács quando estava a escrever sua Ontologia ${ }^{6}$. É verdade, porém, que não podemos falar de distorção principiológica neste caso, pois a definição que citamos de reflexão atribui importância tanto epistemológica quanto ontológica a essa idéia; mas, uma vez que prevê "reflexão" como mero sinônimo de "exercer influência", a "reflexão" irá necessariamente perder a sua especificidade e sua possibilidade de encarnar uma categoria independente. Por outro lado, também é problemático se ambas as expressões de "reflexão" e "reação" supuserem um agente previamente existente, que poderia ter nascido suficiente em si e de si mesmo, de forma a entrar em contato com outros fatores só posteriormente. Isto nos serve para demonstrar que a resposta através da teoria da reflexão obscurece exatamente o fator mais importante da relação entre base e superestrutura, ou seja, o fato de se tratar de uma relação entre os aspectos que, já na origem, foram

6 cf., e.g., com os meus próprios esforços desde o tempo de The Place of Law in Lukács' World Concept (VARGA, 1985, p. 193), o que já foi qualificado por um dos seus revisores, o editor das obras em alemão de Lukács, como uma formulação inicial da teoria autopoiética. Ver Zeitschrift für Rechtssoziologie (BENSELER, 1987/2, pp. 302-304). Para a compreensão da autopoiese em uma reconstrução ontológica do processo aparentemente epistemológico do Direito (ou, propriamente falando, das fronteiras epistemológicas do Direito), cf. VARGA (1995, p. 249). 
desenvolvidos em conjunto, de modo recíproco e em duas direções desde os primeiros pontos do seu desenvolvimento.

Finalmente, houve uma tentativa que procurou dar respostas com base na Ontologia de Lukács, em oposição às simplificações tornadas preconceitos no interior do Marxismo. Assim, "essencialmente, podemos distinguir dois tipos de aspectos recíprocos dentro da totalidade das relações da complexidade social: condicionamento recíproco, por um lado, e determinado por certas condições, por outro; neste último caso, um momento que irreversivelmente pré-condiciona outro". O primeiro tipo de correlação é - numa terminologia lukacsiana - caracterizado pelo predomínio de um momento, e, o outro, pela prioridade ontológica. De acordo com tal conclusão, exclusivamente o último caso diz respeito à economia, uma vez que "existiu um período na história em que a economia funcionou sem regulamentação jurídica e, ainda hoje, existem numerosas áreas e relações da vida econômica sem regulamentação jurídica" (PESCHKA, 1989, pp. 3-4 e 259-274). O esforço do autor da citação, neste caso, visa refutar os preconceitos que quiseram expressar relações entre economia e direito e entre economia e outros setores, como se houvesse, respectivamente, de um lado, conteúdos e, de outro, formas. A tentativa aqui analisada foi plenamente bem sucedida; aliás, a posição de Lukács também é clara: "Forma e conteúdo sempre, em cada tema específico, complexo, processo, etc., determinam em conjunto, e apenas em conjunto, a sua especificidade, seu ser tal como é [gerade-so-sein] (incluídos seus aspectos gerais). É por esta mesma razão que se torna impossível a determinação de complexos reais distintos como sendo um o conteúdo e outro a forma" (LUKÁCS, 1978, p. 151). As minhas dúvidas em relação ao fato de haver ou não distinção entre as influências recíprocas derivam disto. Esta é uma questão decisiva e as respostas em relação a isto são difíceis porque suporia um reexame das razões multidirecionais postas na Ontologia de Lukács e, ao mesmo tempo, teria de considerá-la como algo filosoficamente consistente e coerente do início ao fim.

Mesmo nas últimas décadas que antecederam o já esgotado período "pós-marxista", a filosofia na Hungria não realizou qualquer sério avanço em direção à apreensão de um século das mais importantes 
tentativas marxistas. Então, pode-se dizer que todas as iniciativas não passaram de meditações pessoais. Ainda que Lukács tenha efetivamente falado de prioridade ontológica, ele o fez à revelia da questão que aqui tratamos. Uma vez que admitiu os princípios da construção ontológica de estruturas de Nicolai Hartmann, quando da edificação da ontologia dos complexos, Lukács não poderia deixar de abordar a questão da prioridade ontológica sem se basear na separação das esferas da existência, tal como foi feito. Entretanto, isto não implica que certas complexidades abrangentes necessariamente dêem-se no interior de determinadas esferas da existência, caso em que a afirmação ontológica [seinhaftige] se torna inteligível: "Uma delas pode existir sem a outra, sem que a recíproca seja verdadeira." (LUKÁCS, 1976, p. 31).

Será missão da ainda desejável filologia lukacsiana esclarecer essas inter-relações conceituais. De todo modo, é fato que a questão da prioridade ontológica e da predominância da função desempenhada por qualquer lado que seja no interior desta relação foi elaborada contraditória e inconsistentemente nas páginas da Ontologia do Ser Social de Lukács. Prioridade Ontológica é, por um lado, a caracterização de uma situação em que um fenômeno pode existir sem outro, mas este último não pode existir sem o primeiro; por outro, é a característica de um determinado lado no interior de uma interação que (como o momento predominante) exerce, em última instância, a última e decisiva influência. Lukács se refere à prioridade ontológica, primeiramente, quando fala da distinção entre os modos de existência orgânico, inorgânico e social. Posteriormente, ele menciona a prioridade ontológica no que se tange à relação entre ser e consciência, só para esclarecer brevemente a relação (de novo como prioridade ontológica) em termos de base e superestrutura (Ibidem, p. 147). Ele afirma sutilmente que Marx "não deduz o mundo da consciência com suas formas e conteúdos diretamente da estrutura econômica, mas sim com a totalidade da existência social"; entretanto, Lukács procede como se esquecesse que "a totalidade da existência social" é algo inconcebível sem "o mundo da consciência com suas formas e conteúdos" (Ibidem, p. 32). A situação é bastante semelhante quando 
ele salienta que "a prioridade ontológica da produção, como momento predominante, prevalece em todos os lugares" e ele não vê qualquer inconsistência em recordar isto através do pensamento de que a relação entre a produção e o consumo "significa algo muito próximo das reflexivas determinações discutidas com relação a Hegel” (Ibidem, p. 331). Quando Lukács discute as relações entre processos materiais e "puramente" mentais em relação à produção, prioridade ontológica passa a ser sinônimo de predomínio manifesto na interação: "Quanto mais socializada uma sociedade é, mais inseparavelmente interligados - na produção material - os dois processos são. Ninguém nega suas diferenças ontológicas, mas o fato ontológico primordial dos seus efeitos no âmbito da existência social é que eles inseparavelmente coexistem [...]. Questões de predominância só podem ser razoavelmente levantadas quando a inseparável coexistência é reconhecida na análise deste grupo de fenômenos." (Ibidem, p. 352).

Finalmente, também podemos encontrar exemplos de formas nas quais a real prioridade ontológica se insere num meio em que prevalecem meras interações: "afirmar a prioridade ontológica de um modo de ser em relação a outro não significa, absolutamente, tomar posição, nem positivamente nem negativamente a partir de uma perspectiva de hierarquia de valores. É simplesmente a verificação do fato de que a reprodução biológica da vida forma a base existencial de todas as manifestações da vida, e a primeira sem a segunda é ontologicamente possível, mas o contrário não. A verdadeira resistência contra este simples fato deriva, na verdade, não do fato em si, mas de sua natureza específica compreendida no interior da existência social, da progressiva socialização da existência humano-biológica, da qual resulta, com o tempo, toda uma complexidade que toma forma a partir da reprodução ontogenética no interior do ser social: a esfera da economia. Quanto mais socializadas são as atividades humanas - as quais, no fim das contas, servem para realizar o quanto é requerido pela reprodução bio-ontogenética do homem - tanto mais forte se faz a resistência mental a reconhecer a primazia da esfera econômica sobre as outras." (Ibidem, p. 237). Na mesma medida em que é inequívoco que a reprodução biológica da vida tem prioridade ontológica, 
no sentido de que ela forma a base de todas as outras manifestações da vida, é também menos evidente que a esfera econômica - nas formas socializadas de seu desenvolvimento, ou mesmo em um estágio primitivo - poderia ter nascido e funcionar sem o desenvolvimento da cognição, concomitante à formação das complexidades designadas pela institucionalização da regulamentação e da ordem, e sem interação com essas. Falando de grandes e abrangentes complexos, por exemplo, a função da regulação social pode seguramente ser cumprida não somente por um determinado complexo parcial, distintamente reconhecido como jurídico. Pode ser feito também por formas espontâneas (as quais Lukács já considerou como semi-jurídicas) que garantem, mesmo no caso de uma simples cooperação (por exemplo, o primeiro ato robinsoniano de trabalho), "a mais precisa regulamentação das obrigações dos participantes da base do processo de trabalho concreto e a divisão do trabalho dele decorrente (abatedores e caçadores, por exemplo)" (Ibidem, p. 208). Assim, neste contexto, torna-se irrelevante a questão de determinar quais são as complexidades formadas pelos elementos e funções que, ultrapassando a esfera estritamente fática das relações de produção, são indispensáveis para o funcionamento da economia. Devemos mencionar, porém, um fato importante: para a manutenção de sua reprodução, os seres humanos precisam formar e operar inúmeras outras funções além da produção, a qual eles estão impedidos de abandonar. Ao mesmo tempo, a auto-reprodução humana tem um papel crucial na formação e operacionalização de tais funções.

Voltando às respostas sobre a relação entre base e superestrutura, podemos constatar que todas elas foram, na realidade reducionista, uma tentativa de originar a superestrutura da base econômica. Portanto, se aceitamos o fato de sua inseparável existência como um ponto de referência, então, a única coisa que podemos analisar no âmbito das suas relações como base e superestrutura é o dinamismo da sua interação - estar consciente de que "o fato básico da dialética materialista é que não existe uma verdadeira interação (não há uma verdadeira reflexão-determinação) sem um momento predominante" (Ibidem, p. 333). 
O desenvolvimento filosófico anterior dificilmente pode pretender ter esclarecido a relação entre a prioridade ontológica e momento predominante inerente à referida interação, seja mediante a adoção da utilização das noções lukacsianas ou apontamentos para além destas. É suficiente para suscitar dúvidas acerca dos sentidos mutuamente excludentes da utilização destas noções, a menção do emprego contraditório das expressões na obra de Lukács. Apesar de fornecer alguns caminhos, isto não significa coisa alguma no que diz respeito à comprovação de seus significados de acordo com a estrita definição lukacsiana ${ }^{7}$, pois não se demonstra se se trata de categorias de uma provável oposição ou apenas de uma correlação diferente. À luz da nossa questão inicial sobre a relação entre base e superestrutura, podemos ainda constatar que a existência social é uma complexidade composta de ainda mais complexidades já nos estágios primitivos de seu desenvolvimento e que a existência do ser manifesta irreversibilidade em sua natureza processual e progressiva - sob a forma de interação na qual a complexa cadeia de mediações e justaposições não segue determinações lineares, pois tudo que medeia (em uma determinada direção) é também mediado (em outra direção). Na Ontologia de Lukács, é a categoria da socialização que marca a tendência crescentemente predominante do desenvolvimento - manifesta na complexidade interna crescente da existência social - por meio da gradual tendência à predominância das determinações puramente sociais e por meio das especificidades relativamente independentes de seus elementos. Em conseqüência, na rede de correlações recíprocas, o puramente "material" e o puramente "ideal", ou o "econômico" e outros aspectos - de modo mais abrangente, a "base" e a "superestrutura" - não podem ser separados uns dos outros de maneira que seja possível o primeiro existir sem o último. À primeira vista, isso só é válido para os aspectos mais abrangentes da existência social (isto é, para as suas funções e complexos), e não para suas formas específicas, como religião, arte, política, Direito, ou Estado, que se desenvolvem e se diferenciam uns

7 Prioridade ontológica como a possibilidade da existência do fenômeno não precondicionado pela existência de um outro e o momento predominante como a principal função determinante, exercida dentro das interações reciprocamente precondicionadas. 
dos outros em uma dada fase de desenvolvimento social. Ao mesmo tempo, porém, pode-se dizer que é válido para ambos, uma vez que, tomados como processos desenvolvidos, são irreversíveis (o exemplo de Lukács baseia-se na citação dos Grundrisse de Marx: "O homem é um zoon politicon no sentido estrito da palavra, ele não é somente um animal social, mas um animal que só pode se isolar em sociedade.") (MARX, 1956, p. 6). Isto é para dizer que, uma vez que a existência social tenha se desenvolvido, o desafio prático de qualquer de suas formas só pode ser concebido como a compreensão de uma determinada forma concreta de sociabilidade (assim, eu posso estabelecer a ausência do Estado, Direito, religião ou arte, definidas de uma ou outra maneira, mas isso não alterará a necessidade e o fato de que, de algum modo, algumas formas cumprirão a função de integração da sociedade - ou mesmo auxiliarão a integrar-, regulamentarão suas condições fundamentais, bem como desenvolverão a auto-expressão transcendental e estética dos seres humanos).

Lukács não apresenta uma resposta convincente e definitiva sobre a questão do momento predominante em uma interação específica e de que modo(s) concreto(s) ele se realiza. No entanto, ele afirma, com freqüência, no plano dos princípios, que isso não ocorrerá de forma mecânica, nem em um direto e necessário modo causal. Por outro lado, mantendo-se fiel à tradição genuinamente marxista, ele pretende demonstrar uma teoria social da tomada de decisão, no sentido de apontar que sempre existirão variadas possibilidades de ação. Através da apresentação empírica de exemplos históricos e análises de casos concretos, Lukács pretende demonstrar uma teoria em que as reais decisões resultam das múltiplas mediações e justaposições ${ }^{8}$, mas que sempre se encaminham para uma determinada direção de desenvolvimento. Assim, no processo de determinação social, não são simplesmente fatores externos - força, interesses, etc. - que têm um papel a desempenhar. Tal processo extremamente concreto de auto-determinação necessariamente se dará através da mediação da

8 Ressalte-se que as possíveis alternativas de decisão são sempre tomadas na sua singularidade concreta, mas analisadas num plano social geral; assim, apresentam limites e unidades bem definidas. 
totalidade social, seja por meio do reconhecimento das possíveis alternativas e seu respectivo alcance, seja através do gradual desenvolvimento e auto-afirmação, na prática, das qualidades da personalidade humana (também efetivamente pré-condicionadas pelo próprio processo social total). A variedade dos fatores de influência é bem explicada por Lukács: "Quaisquer que sejam as puras relações imediatas de poder, os homens que as exercem ou que as sofrem são homens que têm de reproduzir suas próprias vidas em determinadas condições concretas; são homens que, conseqüentemente, possuem determinadas aptidões, habilidades, capacidades, etc. que só podem atuar e se adaptar de um modo a elas correspondente. Assim, mesmo que uma nova distribuição da população resulte de relações extra-econômicas de poder, isso jamais ocorrerá independentemente da herança econômica do desenvolvimento anterior - e, assim, nesse caso, uma dupla configuração das novas relações econômicas surgiria necessariamente dessa interação entre os grupos humanos que estão nestes estratos superpostos." (LUKÁCS, 1976, p. 335). Portanto, tudo aquilo que chamamos de momento predominante das interações prevalece largamente apenas através de canais indiretos - nem sempre reconstituíveis por meios exatos. Por esta mesma razão, para a filosofia marxista, ele não pode de modo algum desempenhar a tarefa de redução desses fenômenos complexos a princípios abstratos que podem ser aplicados dedutiva e simplificadamente às diversas áreas do conhecimento humano. Ao contrário, sua função é servir à investigação das formas concretas de interação - aquelas mediações que atuam no interior do âmbito examinado e que conduzem à determinação final - e para investigar o surgimento da específica autonomia do próprio âmbito examinado, identificando essas áreas da realidade, fazendo prevalecer a totalidade social e demonstrando, ademais, o específico movimento dialético de cada um dos âmbitos sociais.

A reciprocidade, desde o início, da relação entre base e superestrutura é suficiente para explicar porque o Marxismo utiliza as categorias de base e superestrutura como uma reciprocidade de categorias mutuamente relativas, destacando, ao mesmo tempo, sempre seu aspecto predominante. Se formos mais longe na análise da complexidade 
dessa definição para alcançar objetivos ainda maiores, livrando sua relação dos traços remanescentes do subjetivismo e do pensamento teleológico; se, além disso, reconhecermos na Ontologia de Lukács uma tentativa de pôr em prática uma perspectiva ontológica que não serve aos propósitos de enrijecer as convicções filosóficas a ponto de torná-las doutrinas e, assim, aplicá-las insensivelmente à realidade; se, pois, chegarmos à conclusão de que a Ontologia de Lukács deve servir para construir nossas próprias noções e ferramentas teóricas, o que verdadeiramente nos ajudará no enfrentamento das questões em aberto; então, vamos também compreender por que razão Lukács não se comprometeu, em seu grande trabalho, a dar continuidade à tradição filosófica que trilha pelas categorias "base e superestrutura" - o que coroaria sua obra - e, por isso, ele só se refere a elas criticamente, ao invés de usá-las em seu próprio raciocínio.

Acredito que este comportamento carrega consigo um posicionamento "tácito", qual seja: o ato de ter retornado à tradição marxista original. Refiro-me à postura metodológica seguida por Marx nos Grundrisse: a análise da correlação concreta deve ser sempre feita dentro do conjunto de categorias concretas em dadas correlações. As categorias base e superestrutura só devem ser utilizadas a título de simplificação na caracterização e síntese de uma determinada parte ou aspecto de algumas correlações. Lukács se expressou em seu próprio sistema de categorias, na linguagem da ontologia de complexos sociais, com uma precisão nunca antes vista, sem utilizar os métodos de descrição metafórica remanescentes de Marx e sem examinar pormenorizadamente os Grundrisse.

Em síntese, a partir das inúmeras relações entre base e superestrutura, as seguintes constatações eram de importância primordial para Lukács:

(1) As várias faces da existência social - especialmente, os fenômenos incorporados pelas categorias de base e superestrutura - estão em um relacionamento no qual elas reciprocamente se condicionam. Trata-se de afirmar que, uma vez que elas são criadas e têm suas especificidades evidenciadas historica- 
mente, elas se tornaram elementos tão intrínsecos à existência social que uma abstração razoável não é mais concebível em relação a elas.

(2) Este condicionamento recíproco se caracteriza pelo processo ininterrupto de interação. Tal processo se torna tão complexo com o avanço do progresso social que a determinação em última instância, que é o aspecto predominante, somente pode prevalecer através de múltiplas mediações. (3) As diferentes complexidades participam no processo e desenvolvem gradualmente as suas especificidades com o avanço da sociabilização; assim, cada vez mais reafirmam sua separação e autonomia relativas. Conseqüentemente, a verdade se tornará mais e mais transparente (de modo a desvendar novas particularidades), uma vez que "cada complexo carrega a característica que lhe permite reagir, a seu próprio modo, aos movimentos ocasionados pelos direcionamentos gerais da existência social na economia" (Ibidem, p. 252). (4) Isso demonstra que a reação de outros complexos sociais parciais não somente é específica (devido a sua estrutura e funcionamento), mas também que o seu próprio passado (com todas as eventualidades inclusas) desempenha um papel determinante na formação de suas características (Ibidem, p. 189). O fato de o passado continuamente construir o presente é de uma natureza ontológica a qual sua forma específica só podemos estabelecer por meio de uma reconstrução posterior, sem ser capaz, pois, de alterar, em nome de qualquer teleologia superior, as formas e os critérios valorativos de seleção, uma vez que a reconstrução foi realizada a partir do passado. Assim, torna-se difícil sustentar que "toda superestrutura social concreta integra apenas os seus antecedentes históricos que correspondem a sua própria base, em seu conteúdo" (ERDÉLYI, 1980, p. 99), a menos que suponhamos a existência de um guardião superior que proporcione alguma racionalidade para o processo em si mesmo. Certas possibilidades de erro, distorções decorrentes do modo ideológico de pensar, recepções irrefletidas e influências decorrentes de certa incapacidade etc. podem ser inerentes a todas as experiências do passado e ao próprio processo de seleção feito a partir dele. As diferentes habilidades, experiência, as formas de reação, os estilos de ação, além dis- 
so, a memória do passado já experimentado - todos esses elementos a construírem de forma irreversível a existência social - inspiraram fortemente Lukács a salientar que só é possível a restauração de uma dada existência social quando condições mecanicamente objetivadas são significativas (LUKÁCS, 1976, p. 115), ou seja, quando são construídas à revelia dos processos sociais. Sob dadas condições específicas, no entanto, é através da mencionada e hipotética restauração que a inadequação das respostas e soluções do passado podem servir como apoios para a construção do futuro ou até se tornarem fatores determinantes deste.

E, neste ponto, o autor deixa de prosseguir em suas conclusões.

Não obstante todas essas considerações, parece-me prudente afirmar que seria desarrazoada uma expectativa de provar qualquer correlação entre as categorias de base e superestrutura na obra de Lukács, ou expô-la filosoficamente de forma que vá além do nível em que o tema foi acima apresentado. Uma das razões para isso é que Lukács criou uma teoria geral no interior da ontologia dos complexos sociais sem antes definir os contornos das teorias relativas às suas áreas (ou complexidades) individuais. Assim, em oposição ao padrão metodológico seguido por Marx, que sempre realizava suas construções teóricas a partir de baixo ${ }^{9}$, Lukács desenvolveu seu pensamento a partir de cima, como se iniciasse a partir de posições teóricas anteriormente estabelecidas, chegando até mesmo, por vezes, a parecer um legatário dos padrões do pensamento dedutivo. Portanto, em oposição ao caminho seguido por $M a r x^{10}$, como pensador, Lukács é um caso específico em que a linha entre o estudioso e o ideólogo não é

9 Na busca de respostas para os problemas de seu tempo, Marx se pautava na análise das condições econômicas e por uma avaliação contínua de suas conclusões frente à experiência concreta. Chegou, pois, a conclusões que apresentaram a história como uma luta de classes e a esfera econômica como força motriz fundamental.

10 Os ideais teórico-científicos e o conhecimento histórico-filosófico de Marx foram formados através de uma série de análises econômicas relacionadas com o máximo de detalhes; suas obras, desde Uma contribuição para a crítica da economia política até O capital, e os mais curtos e simplificados resumos e generalizações, sempre se basearam em análises de situações concretas. 
fácil de traçar. As áreas que ocupavam o centro do interesse profissional de Lukács, distantes da política e da economia - menciono aqui a literatura e a estética -, sempre provocaram certas preferências e preconceitos em toda a sua obra, demonstrando julgamentos normatizados e preconcebidos desde o início. Ao mesmo tempo, naturalmente, Lukács, ao analisar o condicionamento e influência recíprocos entre as diferentes complexidades, aceita a primazia da esfera econômica como princípio fundamental do Marxismo. Mas aquilo que os Grundrisse expõem como a determinação "em última instância" não é apresentado, tampouco explicado, no que concerne às relações recíprocas, pela definição dada por Lukács de "momento predominante". Isto nada mais significa que ele tratou a questão real decorrente da relação entre base e superestrutura como respondida, sem dar maiores explicações, exceção feita quando da defesa da mesma como característica ontológica da existência social em si. Ele a considerou como princípio axiomático de um dado sistema de idéias. E um princípio, como tal, pode apenas ser mencionado no interior de um raciocínio dedutivo, não podendo ser o tipo de categoria a ser utilizada para uma verdadeira e aprofundada investigação.

\section{O TRATAMENTO DO DIREITO}

A tradição marxista, expressando as relações da sociedade por meio das categorias de base e superestrutura, é tão forte em todo o mundo e especialmente na região da Europa Central e Oriental que a teoria jurídica deve inevitavelmente se defrontar com a concepção do Direito como superestrutura. Os caminhos tradicionais deste conceito - ou a herança verdadeiramente forçada de tais caminhos - já são tão recorrentes que um ponto de vista exterior poderia ter a sensação de estar lidando com um tipo de "uma teoria geral quase-econômica e determinista” (ERH-SOON TAY, KAMENKA, 1980, p. 268). É fato que, na nossa região, os principais temas tratados na base de toda teoria jurídica até os nossos dias tem sido a relação entre Direito e Economia (em bom Marxismo) e a exposição teórica de como os sistemas jurídicos pertencentes a diferentes formações sócio-econômicas podem 
exercer influência um sobre o outro (nos últimos períodos do Marxismo, a especulação sobre os sentidos e formas de desenvolvimento ${ }^{11}$ do Direito, descritos por Alan Watson, fizeram com que tais questões fossem postas na ordem do dia ${ }^{12}$ ). É também fato que isto seria uma tarefa da ciência marxista do Direito (isto é, desde que a ciência jurídica marxista possa sobreviver à queda do "socialismo realmente existente" na região da Europa Central e Oriental) que, então, habilitar-se-ia a, finalmente, realizar uma pesquisa histórica: examinar por meios comparativos, com base em material histórico concreto, o desenvolvimento das respectivas soluções dadas por decisões judiciais e seus respectivos ordenamentos jurídicos, bem como a linha e lógica deste desenvolvimento. A análise de vários institutos jurídicos fornece informações adicionais que possibilitam responder à pergunta: que papel determinante, de "última instância", pode a economia desempenhar na esfera jurídica?

Ser capaz de explicar a relação contraditória entre Direito e economia, por um lado, e os efeitos dos diferentes sistemas jurídicos uns sobre os outros, por outro, requer, em primeiro lugar, a clareza do conceito de Direito como uma superestrutura geral e diferenciada.

Quanto à sua diferenciação, até o final do anos 60, a teoria jurídica socialista, mantendo distância em relação ao últimos defensores do dogma stalinista no que diz respeito à descontinuidade total entre as diferentes espécies de Direito (cf. ARLT, LUNGWITZ, 1963), chegou à conclusão de que o Direito é realmente dicotômico, sendo formado por conteúdos sociais e normativos (cf. PESCHKA, 1965; DONGOROZ, 1965; NASCHITZ, 1966; SZOTÁCZKI, 1970, NENOVSKI, 1975). Este ponto de vista foi abordado a partir de variadas direções. Alguns

11 Para uma visão geral das influências interculturais no desenvolvimento jurídico, cf. Comparative Legal Cultures, organização e introdução de Csaba Varga (1992, xxiv, p. 614) [The International Library of Essays in Law \& Legal Theory, séries organizadas por Tom D. Campbell, Legal Cultures 1] e European Legal Cultures, (GESSNER, HOELAND, VARGA, 1996, xviii, p. 567) [Tempus Textbook Series on European Law and European Legal Cultures I].

12 O tema foi apresentado por Csaba Varga em artigo sobre a "Transposição de Direitos: a internalização como fator Universal do Desenvolvimento Jurídico" [em húngaro] (1980, pp. 286-298). 
começaram a partir da tese de que o Direito é reflexo da realidade, sendo assim o espelho imediato dela em termos de conteúdos sociais; estes devem ser transformados em conteúdos indiretos (normativos) para poderem se expressar como Direito e, assim, servir de influência jurídica nas diversas complexidades sociais (PESCHKA, 1965). Outros começaram a partir da dialética de meios e fins. Estes alegaram que o Direito só pode cumprir seu papel através de suas próprias funções técnico-jurídicas (NENOVSKI, 1975). Ambos argumentos acima expostos contêm alguns elementos de verdade; porém, ainda acredito que nenhum deles forneceu explicação suficiente, uma vez que entenderam o Direito somente como a totalidade dos instrumentos normativos e judiciais, como uma superestrutura estática, ou seja, como um mero conjunto de diplomas legais (quer sejam expressamente pertencentes ao ordenamento jurídico, quer sejam com este compatíveis).

No que diz respeito à natureza genérica do conceito de superestrutura jurídica, a teoria apenas recentemente chegou a um ponto em que se tornou capaz de reconhecer que as características relativas à totalidade da superestrutura não podem ser restritas a (nem deduzidas de) elementos individuais de uma determinada superestrutura. Assim, uma formulação se segue: "a natureza jurídica superestrutural de uma parte da superestrutura não pode, por um lado, ser considerada como algo desconectado de normas jurídicas específicas; por outro, tais normas específicas não podem ser consideradas independentemente, ainda que tomadas em sua singularidade. A função da superestrutura compreende a totalidade e a generalidade concreta de um determinado fenômeno social" (SZABÓ, 1973[sem referência de página no original]) - bem, essa formulação não resolve o dilema básico nem mostra o caminho de saída do mesmo. Limita-se a confirmar o fato de que a natureza da superestrutura nasce de certas objetivações: em parte das normas sancionadas e, em parte, das instituições jurídicas oficiais.

A partir da perspectiva jurídico-filosófica posta na Ontologia de Lukács (VARGA, 1985), poderemos chegar a resultados de longo alcance, inovadores no que diz respeito a sua perspectiva metodológica e a sua abordagem teórica. Nesse sentido, o Direito 
(1) do ponto de vista ontológico, é um processo irreversível. Seu movimento é definido principalmente por seu lugar no complexo da totalidade social - dentro deste, através de várias mediações político-sociais e outros tipos de mediações - e por sua relação com a esfera da economia.

(2) O movimento no interior do complexo social total apresenta, em nível de determinados complexos parciais específicos, uma reprodução contínua de uma unidade dialética que articula estabilidade e mudança.

(3) A partir de uma perspectiva ontológica, a existência social do complexo do Direito pode ser reduzida a sua real atividade de influência social. (Assim, o atual Direito húngaro não é apenas a soma das disposições legais em vigor, não é apenas a organização judiciária com o seu pessoal e sua burocracia institucional, mas a soma desses dois no seu funcionamento real, influenciando a vida social e configurando um elemento desta.) Assim, nem todo componente fundamental, nem toda forma de objetivação e nem toda regra interna do Direito necessariamente apresenta influência social.

(4) Por conseguinte, pode ou não haver equivalência entre o Direito enquanto possível efetivação e o Direito em seu funcionamento real, isto é, entre o Direito tomado como uma reunião de instrumentos técnicos (o plano organizacional-institucional dos mecanismos aptos a exercer influência, ou seja, as disposições legais e a burocracia dedicada a sua promulgação e aplicação) e o Direito tomado como a realização das suas funções intrínsecas (seu movimento e efeito social reais, a forma real que o Direito assume na vida prática da sociedade).

(5) O passado em certo momento é verdadeiro para o presente tanto quanto possamos agir em conformidade a ele. Assim, o progresso humano - bem como em relação à soma dos instrumentos técnicos disponíveis - manifesta-se muito mais quando da recolocação de elementos antigos em novo contexto - habilitando-os a influenciar novos mecanismos - que na própria formação e utilização de novos elementos ${ }^{13}$.

13 Segundo Naschitz, o "fator humano", e, de acordo com Nenovski (Cap. VII-VIII), a "existência social", ou ainda o "fenômeno sociológico do controle social em todas as 
(6) A partir das considerações acima descritas, conclui-se que não podemos de forma alguma desconsiderar o caráter instrumental do Direito. Além disso, simultaneamente, temos de discutir com a mesma ênfase os vários tipos de aspectos sociológicos, morais, econômicos e políticos inerentes ao uso instrumental do Direito, bem como a questão da adequação entre os objetivos a serem alcançados e os instrumentos utilizados.

(7) A partir de uma perspectiva ontológica, o Direito é um fenômeno uno por duas razões, não obstante a sua complexidade interna. Por um lado, suas formas de objetivação só podem ser avaliadas através do seu funcionamento e ação reais; por outro, da mesma forma, seus princípios internos, valores instrumentais e complexidade estrutural (independentemente do quanto eles são histórica e concretamente bem definidos e independentemente de haver ou não mais de uma forma de serem efetivados) podem ganhar importância ontológica exclusivamente através da sua efetiva realização e funcionamento. Ou seja, independentemente dos limites que a ordem jurídica interna traça entre os respectivos processos de elaboração e aplicação da legislação, apenas aqueles que sejam instrumentalizados na prática social real irão prevalecer, de modo a serem perceptíveis ontologicamente.

(8) Isto implica também que a dialética da estabilidade e mudança pode ser posta em ação apenas no contexto da totalidade do complexo jurídico. Por esta razão, não podemos alegar que as mudanças podem ser desencadeadas exclusivamente pelas alterações de legislação (oficialmente institucionalizada para cumprir este fim), ou seja, somente pela promulgação da lei de acordo com um procedimento e da forma prescrita pelos diplomas legais. Além disso, também não podemos dizer que as mudanças sejam efetivadas somente por seus instrumentos jurídicos específicos (também oficialmente institucionalizados para este fim); ou seja, o estabelecimento e a execução das conseqüências jurídicas de um determinado ato não decorrem somente de procedimentos e formas prescritas pelos

formações sociais", são os momentos explicativos para o caso de diferentes sociedades com tradições também diferentes chegarem a soluções comuns ou, no mínimo, semelhantes, em termos jurídicos. 
diplomas legais estabelecidos. $\mathrm{Na}$ análise final, o movimento em um dado momento do complexo social total e a complexidade interna do complexo jurídico parcial (a sua tradição, a complexidade estrutural e seu peso relativo, bem como a sua força interna para exercer uma influência socialmente desejável mediante o cumprimento de suas próprias normas) irão definir a forma como o complexo jurídico reagirá aos desafios externos de continuidade e mudança.

No domínio do Direito, como um campo que opera um conjunto formal de meios conforme padrões procedimentais formalizados, a resposta aos desafios postos por outro complexo social parcial, ou seja, a forma de reagir própria ao Direito, é preponderantemente alcançada através da manipulação do conjunto de meios já disponíveis, em que pese as possíveis alterações individuais de um ou outro meio resultante da interação do Direito para com um dado complexo social parcial. Na sua reconstrução ontológica, no entanto, o contínuo processo de manipulação dos meios também pressupõe uma incessante transformação das características reais dos instrumentos disponíveis e relevantes ${ }^{14}$, o que altera, por conseguinte, também o significado, a importância e os resultados sociais da implementação dos referidos meios.

\section{BIBLIOGRAFIA}

ARLT, Reiner. LUNGWITZ, Wolfgang. "Die Entwicklung des sozialistischen Rechts und die biirgerliche Traditionen". In: Staat und Recht, $1963 / 5$.

BARASCH, Eugene. "Les constantes du droit: Droit et logique", Revue des Sciences sociales: Série de Sciences juridiques, VIII, 1964.

14 Para as formas em que a complexidade do Direito reproduz a si mesma respondendo variavelmente à evolução das necessidades percebidas socialmente, cf. VARGA (1999, vii +279 ), em particular os caps. V-VII [Philosophiae iuris]; como coletânea de artigos complementares do autor, ver $A$ jog folyamat [O Direito enquanto processo] (1999, p. 430). 
BAUMAN, Zygmunt. Általános szociológia [Sociologia em Geral] [Zarys marksistowskiej teorii spoleczentswa, Warsaw, PWN 1964]. Budapest: Kossuth, 1967.

BENSELER, Frank. Zeitschrift für Rechtssoziologie 8, 1987. 2.

DONGOROZ, Victor. "Dreptul penal socialista al tarii noastre: Raportul dintre continutul normativ si continutul social-politic al dreptului penal din Republica Socialista Romanin" Siudii si cercetari juridice, 1965/3.

ENGELS, Friedrich. MARX, Karl. 'Zur Kritik der politischen Ökonomie"' [1859]. In: Ausgewahtte Schriflen I. Moscou: Verlag fur Eremdsprachige Literatur, 1951.

ERDÉLYI, Lajos. "Alap és felépítmény" [Base e superestrutura] in Tortenelmi materializmus [Materialismo histórico]. Budapest: Kossuth, 1980.

ERH-SOON TAY, Alice. KAMENKA, Eugene. "Marxism-Leninism and the Heritability of Law". In: Review of Socialist Law, VI, 1980, 3.

GRAMSCI, Antonio. "Il materiailismo storico e la filosofia di Benedetto Croce". In: Opere 2, 8a ed. Roma, 1966.

HOLZ, Hans. KOFLER, Leo. ABENDROTH, Wolfgang. Conversations with Lukács. Organiza ção de Theo Pinkus. Londres: Merlin, 1974.

KALLÓS, Miklos. ROTH, Endre. A társadalmi rendszer [Sistema Social], Bukarest: Politikai Konyvkiado, 1978.

KÁRPÁTI, Sandor. A társadalom gazdasági alapja és felépilménye [A base econômica e a superestrutura de uma sociedade]. Budapest, 1982.

LUKACS, György. A társadalmi lét ontológiájáról [Zur Ontologie des gesellschaftlichen Seins] III [Prolegomena: Prinzipienfragen einer heute möglich gewordenen Ontologie]. Budapest: Magvetó, 1976.

Marx’s Basic Ontological Principles. Tradução de David Fernbach. Londres: Merlin, 1978.

MAKEPEACE, R. W.: Marxist Ideology and Soviet Criminal Law. Londres, Totowa e Nova Jersey: Croom Helm, Barnes e Noble, 1980. 
MARX, Karl. Grundrisse der Kritik der politischen Okonomie (Rohentwurt) 1857-1858. Berlim: Dietz, 1953.

NASCHITZ, Anita. "Le problème du droit naturel" à la lumière de la philosophic marxiste du droit" Revue roumaine des Sciences Sociales: Série de Sciences juridiques X, 1966.

NENOVSKI, Neno. Priemstvenosta $v$ pravoto [A continuidade no Direito]. Sofia: Nauka i Izkustvo, 1975.

PESCHKA, Vilmos. Jogforrds es jogalkotds [Fontes e criação do Direito]. Budapeste: Akadémiai Kiadó, 1965.

. "Ideologische Vorurteile über das Verhältnis zwischcen Wirtschaft und Recht". In: Acta Juridica Academiae Scientiae Hungaricae, 1989

PHILLIPS, Paul. Marx and Engels on Law and Laws. Oxford: Robertson, 1980.

RÓNAI, Róbert. Alap és felépítmény [Base e superestrutura]. Budapest, 1973.

SZABÓ, Imre. Les fondements de la théorie du droit. Budapest: Akadémiai Kiadó, 1973.

SZOTÁCZKI, Mihály. A jog lényege [A essência do Direito]. Budapeste: Közgazdasági és Jogi Kiadó, 1970.

VARGA, Csaba. The Place of Law in Lukács' World Concept, Budapeste, Akadémiai Kiadó, 1985 [reimpresso em 1998].

. "A jog mint felépítmény: Adalékok az alap-felépítmény kategoriápár történetehez " [O Direito como superestrutura: uma contribuição à história do par de categorias base e superestrutura] In: Magyar Filozófiai Szemle XXX. 1986.

. Transition to Rule of Law. On the Democratic transformation in Hungary. Budapeste: Akaprint, 1995. 
. Theory of Judicial Process: The Estabilishment of Facts. Budapest: Akadémiai Kiadó, 1995.

et alii (Org.). Comparative Legal Cultures. Aldershot, Hong Kong, Cingapura, Sydney, Dartmouth e Nova York, New York University Press, 1992.

. "Transposição de Direitos: a internalização como fator Universal do Desenvolvimento Jurídico" [em húngaro]. In: Allam - és Jogtudomány XXIII, 1980.

- Paradigms of Legal Thinking. Budapeste: Akadémiai Kiadó, 1999.

A jog folyamat [O Direito enquanto processo]. Budapeste: Osiris, 1999.

Recebido: 1\% $\%$ /2016

Aceito: 02/05/2016 